\title{
LA RUPTURA DEL EQUILIBRIO CONTRACTUAL: HACIA UNA TENDENCIA COMÚN DESDE DIFERENTES DERECHOS NACIONALES
}

\author{
EDUARDO HERRERO URTUETA \\ PROFESOR DE DERECHO MERCANTIL \\ UNIVERSIDAD DE LA RIOJA \\ eduardo.herrero@unirioja.es
}

SUMARIO: I. INTRODUCCIÓN. II. LOS PRINCIPIOS UNIDROIT. III. EL COMMON LAW: DE LA FRUSTRACIÓN DEL CONTRATO INGLESA A LA IMPRACTICABILIDAD NORTEAMERICANA. IV. LA DOCTRINA ALEMANA DE LA BASE DEL NEGOCIO. V. LA DOCTRINA DE LA IMPREVISIÓN FRANCESA. VI. LA EXCESIVA ONEROSIDAD ITALIANA. VII. LA CLÁUSULA REBUS SIC STANTIBUS. VIII. CONCLUSIÓN. IX. BIBLIOGRAFÍA

RESUMEN: Uno de los pilares básicos del derecho contractual es el principio pacta sunt servanda, el cual establece la obligatoriedad de cumplir con lo suscrito en el contrato. Sin embargo, la situación actual de pandemia global ha vuelto a poner en primera línea diversas instituciones que matizan ese principio en casos de grave desequilibrio contractual. Por este motivo, es necesario realizar un estudio comparado de diversas figuras como la cláusula rebus sic stantibus, la impracticability o la excesiva onerosidad, que quiebran uno de los pilares fundamentales del derecho de contratos con el fin de establecer la existencia de cierta tendencia común a su incorporación a los ordenamientos jurídicos.

PALABRAS CLAVE: pacta sunt servanda, alteración de circunstancias, excesiva onerosidad, rebus sic stantibus, frustration.

\section{THE BREAKING OF THE CONTRACTUAL BALANCE: TOWARDS A COMMON TREND FROM DIFFERENT NATIONAL LAWS}

ABSTRACT: One of the basic pillars of contract law is the principle of pacta sunt servanda, which establishes the obligation to comply with the contract. However, the current situation of global pandemic has brought back to the forefront some institutions that break this principle in cases of serious contractual imbalance. For this reason, it is necessary to carry out a comparative study of some figures such as the rebus sic stantibus clause, impracticability or hardship, which break one of the fundamental pillars of contract law in order to establish the existence of a certain common trend towards its incorporation into legal systems.

KEY WORDS: pacta sunt servanda, change in circumstances, hardship, rebus sic stantibus, frustration. 


\section{Introducción}

De todos es conocido el principio pacta sunt servanda, un pilar básico del derecho contractual que pone de manifiesto la esencia más fundamental del derecho de los contratos, esto es, los contratos deben cumplirse ${ }^{1}$. Al fin y al cabo, todo el derecho de las obligaciones gira en torno a la premisa en que las partes suscriben un pacto de forma libre con el objetivo de obligarse y quedar vinculadas por lo establecido en el contrato.

Sin embargo, este principio que, constituye un pilar fundamental del derecho de contratos y, parecía que era imperturbable, ha tenido, desde hace tiempo, una confrontación con diferentes instituciones jurídicas que han ido surgiendo, normalmente en épocas de crisis, y que matizan lo absoluto de dicho principio. Así, han ido surgiendo determinadas instituciones que interpretan la voluntad de las partes de obligarse, teniendo presente el entorno y las circunstancias existentes alrededor del contrato. Como consecuencia de ello, la voluntad emitida en el momento de suscribir el contrato se hace teniendo en cuenta las circunstancias existentes y las posibles variaciones que puedan preverse, de tal manera que, en caso de eventos imprevisibles que afecten al contrato podrían interpretarse como alteradores de la manifestación del consentimiento. Por consiguiente, en caso de una modificación sustancial de las circunstancias del contrato, podría conllevar a inferir que la voluntad emitida en su día por las partes, quedaría viciada en cierta manera.

De este modo, tanto en el ámbito internacional como en los diferentes derechos nacionales, el derecho de contratos ha ido evolucionando y construyendo una serie de instituciones que vienen a matizar el principio pacta sunt servanda.

A nivel internacional destacan figuras como el hardship y la excesiva onerosidad regulada en los Principios UNIDROIT, al igual que la extensión de las cláusulas hardship que incorporan las citadas instituciones al contrato.

En cuanto a nivel nacional, existen numerosas figuras en los principales ordenamientos jurídicos, que cada vez cobran mayor auge, como es el caso de la cláusula rebus sic stantibus que va cobrando mayor relevancia en la actualidad como consecuencia de la situación de crisis en la que el mundo se encuentra actualmente.

De todo lo anteriormente expuesto se puede observar la pluralidad de instituciones que han ido surgiendo en sede de diferentes derechos nacionales y, además, en sede de instrumentos internacionales, con el fin de adecuar el principio pacta sunt servanda ${ }^{2}$. Por este motivo, es preciso realizar un estudio comparado de las diversas instituciones con el fin de determinar el punto en que se encuentran y cuál es la tendencia de futuro, en aras de poder establecer si existe cierta tendencia común a la incorporación de estas instituciones en el derecho contractual.

\footnotetext{
1 FERNÁNDEZ RUIZ-GÁLVEZ, E., "La alteración sobrevenida de las circunstancias contractuales y la doctrina rebus sic stantibus. Génesis y evolución de un principio jurídico”, Persona y derecho: Revista de fundamentación de las Instituciones Jurídicas y de Derechos Humanos, 74, 2016, págs. 291-318, pág. 293.

${ }^{2} \mathrm{El}$ principio pacta sunt servanda se encuentra contrarrestado por diversas instituciones como la rebus sic stantibus en aras de matizar dicho principio absoluto en aras de la equidad y la justicia en las relaciones contractuales. FERNÁNDEZ RUIZ-GÁLVEZ, E., "La alteración sobrevenida de las circunstancias contractuales y la doctrina rebus sic stantibus. Génesis y evolución de un principio jurídico", Persona y derecho: Revista de fundamentación de las Instituciones Jurídicas y de Derechos Humanos, 74, 2016, págs. 291-318, pág. 300.
} 


\section{Los Principios UNIDROIT}

El análisis de este tipo de instituciones debe comenzar con uno de los instrumentos principales a nivel internacional de derecho de contratos, esto es, los Principios UNIDROIT.

Los principios UNIDROIT son sumamente conocidos por su gran extensión en el ámbito del derecho contractual internacional, al constituir un conjunto de principios generales de amplia utilización en los contratos internacionales, siendo parte de la denominada Lex Mercatoria ${ }^{3}$. Como consecuencia de su gran relevancia, suponen un punto de referencia del que partir en el análisis de este tipo de instituciones que se abren hueco en materia contractual.

En este sentido, resulta relevante establecer que los Principios UNIDROIT articulan la figura del hardship y la excesiva onerosidad como una excepción o matización al principio pacta sunt servanda, en la medida en que establecen dicho principio con las excepciones originadas por el hardship y la excesiva onerosidad.

Así, partiendo de la obligatoriedad de los contratos establecida en el art. 6.2.1 de los Principios UNIDROIT, se articula la excesiva onerosidad como un grave desequilibrio generado por determinados eventos que alteran el equilibrio contractual, contemplada en el art. 6.2.2. De tal modo que dichos eventos deben ser imprevisibles y ser conocidos después de la celebración del contrato. No obstante, los presupuestos no terminan aquí, en la medida en que dichos eventos no deben ser asumidos dentro del riesgo contractual de las partes, por lo que el análisis de la esfera de control será imprescindible para poder determinar la aplicación de esta institución.

Por todo ello, es necesario detenerse a analizar estos requisitos que permitirán aplicar lo previsto por los Principios UNIDROIT a las situaciones de excesiva onerosidad. En relación al grave desequilibrio entre las partes, es un requisito que hace referencia a las prestaciones que los intervinientes en el contrato han contraído. Como consecuencia, es un requisito que, en ocasiones, podrá ser fácilmente medible puesto que tendrá determinadas repercusiones económicas. Así, el encarecimiento de los precios o el aumento exorbitado de aranceles que encarezcan enormemente la transacción, son desequilibrios medibles económicamente, de tal modo que permiten al observador examinar de una manera más objetiva si se produce una desproporción de calado ${ }^{4}$. No obstante, pese a determinadas situaciones en que pueda ser más sencillo analizar el desequilibrio, habrá que atenerse al criterio de la razonabilidad que habilita para interpretar la situación y valorar la concurrencia del citado desequilibrio ${ }^{5}$.

Tras constatar la existencia de un gran desequilibrio, es necesario delimitar el origen del mismo, en la medida en que debe ser posterior a la suscripción del contrato y resultar imprevisible. Este requisito entronca, por su similitud, con determinadas instituciones conocidas como son la fuerza mayor y el caso fortuito. Así, la fuerza mayor se define como aquel suceso que es inevitable, aunque se emplee toda la diligencia por evitarlo y haya sido previsto. En cuanto al caso fortuito, se

\footnotetext{
${ }^{3}$ ILLESCAS ORTIZ, R., \& PERALES VISCASILLAS, P. (2003). Derecho mercantil internacional. El Derecho uniforme. Madrid: Centro de Estudios Ramón Areces, 2003, pág. 83.

${ }^{4} \mathrm{Al}$ respecto, se ha considerado incardinable en esta institución el incremento repentino y desproporcionado de las materias primas. DÍEZ SOTO, C.M.; GONZÁLEZ PACANOWSKA, I.V., "Los principios de UNIDROIT sobre los contratos comerciales internacionales y los efectos derivados del Covid-19 sobre las relaciones contractuales: una perspectiva desde el Derecho español”, Cuadernos de derecho transnacional, 1, 2021, págs. 180-237, pág. 217.

${ }^{5}$ En algún fallo en el seno del derecho uniforme, se ha llegado a afirmar que este tipo de instituciones se vinculan estrechamente con el principio de buena fe contractual. Hof van Cassatie, Bélgica, 19 de junio de 2009 (Scafom International BV v. Lorraine Tubes S.A.S.)
} 
trata del evento que resulta totalmente imprevisible, aun contando con la mayor de las diligencias. Por consiguiente, se puede observar una estrecha similitud entre estas dos figuras y los requisitos de imprevisible, inevitable y fuera de la esfera de control que deben acreditarse respecto a los eventos generadores de una excesiva onerosidad.

Así, para la concurrencia de estos requisitos, será preciso que un observador entienda que dichos eventos no pudieron ser razonablemente previsibles o evitables por la parte afectada, de tal modo que se entroncaría con cuestiones tales como la debida diligencia. Además, hay que recordar que dichos eventos no deben incluirse en un riesgo que deba ser asumido por las partes.

Tras examinar los requisitos que deben concurrir para la excesiva onerosidad, es necesario analizar las consecuencias de su reconocimiento. Ante esta situación de gran desequilibrio se plantean dos posibles soluciones: readaptación del contrato o extinción del mismo.

Esta dicotomía de opciones presenta un problema de partida en la medida en que una institución que surge para matizar el principio pacta sunt servanda pueda extinguir el contrato, resulta algo "radical"'. Por este motivo, la opción por la que se inclinan los Principios UNIDROIT es la readaptación o renegociación del contrato, de manera que se articula un principio favor contractus, en aras de mantenerlo vigente. Al fin y al cabo, el desequilibrio genera una frustración del fin del contrato, por lo que si desaparece el desequilibrio, se podría mantener la vigencia del mismo.

No obstante, dado que la práctica contractual resulta sumamente compleja, se permite la extinción del contrato para los casos en que dicha readaptación contractual no sea posible y no haya otra vía que dar por finalizada la relación contractual.

Este sistema orquestado por los Principios UNIDROIT resulta sumamente relevante por dos motivos. El primero de ellos trae causa de la gran expansión y utilización de dicho instrumento, lo que genera que esta institución del hardship y la excesiva onerosidad se vaya extendiendo de una forma armónica en la práctica contractual. El segundo de los motivos, se encuentra íntimamente relacionado con el primero, puesto que la expansión de los Principios UNIDROIT tiene su origen en la neutralidad jurídica, ya que tratan de incorporar instituciones de manera que puedan aplicarse y coordinarse con diferentes familias jurídicas7. Así, esta institución se ha visto inspirada por la correspondiente del Derecho norteamericano, del Derecho alemán, del Derecho francés y del Derecho italiano, motivo por el que deben ser estudiadas las correspondientes instituciones nacionales ${ }^{8}$.

\footnotetext{
${ }^{6} \mathrm{El}$ principio pacta sunt servanda constituye un pilar del derecho de contratos, motivo por el que alguna doctrina considera que la posibilidad de variar el contrato o extinguirlo como consecuencia de este tipo de situaciones es un primer paso que rompe con la clásica sacralización del contrato. TIMOTEO, M., "Desequilibrios contractuales y adecuación del contrato en los Principios UNIDROIT", Revista de Derecho Mercantil, 228, 1998, págs. 1269-1284, pág. 1280.

${ }^{7}$ En este sentido se han pronunciado autores indicando que en su redacción se trata de coordinar las diferentes figuras del Common Law y del Civil Law. VIGURI PEREA, A., Los contratos comerciales internacionales: análisis de la compraventa desde la perspectiva del derecho comparado (Derecho español, Derecho norteamericano, Principios Unidroit y Convención de Viena). Madrid: Centro de Estudios del Colegio de Registradores de la Propiedad y Mercantiles de España, 2007, pág. 11.

8 TIMOTEO, M., "Desequilibrios contractuales y adecuación del contrato en los Principios UNIDROIT", Revista de Derecho Mercantil, 228, 1998, págs. 1269-1284, pág. 1277.
} 


\section{El Common Law: de la frustración del contrato inglés a la impracticabilidad norteamericana}

El Common Law es uno de los sistemas jurídicos más extendidos a nivel internacional pero no es uniforme, motivo por el que es necesario tener presentes los dos ordenamientos principales que sirven como referencia de dicho sistema, es decir, el derecho inglés y el derecho norteamericano.

En cuanto al derecho inglés, es preciso hacer mención a su origen como derecho fuertemente influenciado por los comerciantes. Este origen fundamenta y determina la postura que ostenta el derecho inglés respecto a este tipo de instituciones tales como la excesiva onerosidad y similares?. Por ello, es reseñable que el derecho inglés constituye un ordenamiento sumamente respetuoso con el principio pacta sunt servanda, constituyendo un pilar fundamental de su sistema contractual, casi con mayor rigidez que en el Civil Law.

Así, en el derecho inglés se construyó la regla Paradine que establecía el principio pacta sunt servanda de forma absoluta, siendo sumamente garantista con los $\operatorname{contratos}^{10}$. Esta postura tan absoluta frente al cumplimiento de los contratos genera disfuncionalidades o injusticias cuando se generan determinados eventos, lo que constituye el resquicio que permite alguna matización de la regla Paradine.

En este contexto se construye la doctrina de la frustración del propósito o frustration, una postura que permite cierta flexibilidad al absolutismo previo que existía en el derecho inglés acerca del cumplimiento de los contratos. La frustration se define cuando el Derecho, sin que medie incumplimiento de las partes, reconoce la imposibilidad de cumplir alguna obligación, puesto que, como consecuencia de alguna alteración de las circunstancias, la obligación se convierte en algo radicalmente distinto al compromiso asumido por la parte ${ }^{11}$.

Vista la definición de la frustration, hay que resaltar que se trata de una doctrina de construcción jurisprudencial, dada la particularidad del derecho inglés. Así, se ha ido aplicando esta doctrina pero con diversas fundamentaciones. Por este motivo, se han conformado varias teorías sobre la frustration que atienden al mismo problema desde diferentes puntos de vista ${ }^{12}$.

La primera de ellas es la teoría de la cláusula implícita que considera que hay una suerte de cláusulas subyacentes en el contrato que, si desaparecen, se produciría la frustration. Así, esta teoría establece que de las circunstancias en el momento del contrato y alrededor de las partes, se puede inferir una suerte de condiciones implícitas, de modo que si se ven afectadas se frustra el contrato y éste decae. Así pues, esta postura analiza el contrato con el objetivo de esclarecer una serie de circunstancias que, de no producirse, evitarían la prestación del consentimiento de las partes, de modo que lo que no habrían previsto acerca del contrato podría frustrar el mismo. Lo interesante de esta postura es que se ha estudiado desde un punto de vista subjetivo, centrándose en las circunstancias que construyen la premisa para el consentimiento o, desde un punto de vista objetivo, valorando las

\footnotetext{
${ }_{9}$ GARCÍA CARACUEL, M., La alteración sobrevenida de las circunstancias contractuales, Madrid, Dykinson, 2014, pág. 63.

${ }^{10}$ La regla Paradine tiene su origen en el asunto Paradine vs Jane de 1647 en el que se consagra la rigidez del derecho de contratos inglés reduciendo el ámbito de la frustration. GARCÍA CARACUEL, M., La alteración sobrevenida de las circunstancias contractuales, Madrid, Dykinson, 2014, pág. 67.

11 KATSIVELA, K., "Frustration and impracticability under English, United States (US) and Canadian common law of contracts”, European Transport Law, 1, 2009, págs. 3-27, pág. 4.

12 GARCÍA CARACUEL, M., La alteración sobrevenida de las circunstancias contractuales, Madrid, Dykinson, 2014, págs. 75-86.
} 
circunstancias alrededor del contrato consideradas por las partes y su anticipación, el punto de vista del reasonable man.

Otra teoría es la teoría de la desaparición sobrevenida de la causa que vincula la frustration con la desaparición de la consideration. Esta última que supone el fundamento del propósito del contrato y la causa por la que se manifiesta el consentimiento genera el decaimiento del contrato si se extingue por, por ejemplo, la desaparición del interés económico del contrato.

La teoría de la solución justa y razonable queda íntimamente ligada con lo comentado anteriormente acerca del surgimiento de la doctrina de la frustration como herramienta que atenúe las injusticias que generaba la aplicación de la absoluta regla Paradine. Por este motivo, esta teoría acude a criterios como la equidad con el objetivo de matizar el contrato y restablecer el equilibrio.

También se puede ver la frustration desde el punto de vista de la teoría de la desaparición de la base del contrato, es decir, analizar el alcance del compromiso asumido por las partes y hasta dónde alcanza con el nuevo paradigma. En caso de considerar que la nueva situación no se encuentra amparada por lo contemplado por las partes, se entendería que ha desparecido la base del contrato, motivo por el que decae. Esta teoría resulta similar con la doctrina alemana de la base del negocio.

Finalmente, se construye la doctrina de la frustration mediante la teoría de la interpretación fiel del contrato. Esta postura, pretende hacer una labor hermenéutica del contrato y la voluntad de las partes, comparando la situación en el momento de contratar con la situación tras la alteración de circunstancias, de manera que, si se puede observar un cambio significativo, se estimaría la doctrina de la frustration.

Pese a las numerosas teorías que se han venido aplicando en el derecho inglés respecto a la frustration en una búsqueda de una doctrina que permita matizar el principio pacta sunt servanda, no es una doctrina que sea acogida de forma amplia por la jurisprudencia. Por lo que se han ido construyendo una serie de límites alrededor estableciendo situaciones en las que, pese a ser incardinable, no resultaría de aplicación por diferentes motivos ${ }^{13}$. Así, las partes pueden evitar la aplicación de esta doctrina mediante el uso de determinadas instituciones contractuales como la transmisión del riesgo. Al fin y al cabo, la transmisión del riesgo es un mecanismo contractual que reparte los riesgos del contrato de tal modo que la parte afectada deberá asumir los perjuicios, ya que le corresponde por el reparto de riesgos ${ }^{14}$. Además, es vital tener presente que este tipo de instituciones no aplican en caso de haber determinadas conductas de las partes que no hayan sido todo lo diligentes que debieran ${ }^{15}$. En este sentido, hay que ser consecuentes y recordar que estas instituciones surgen como medio para paliar determinadas "injusticias" que generaría el cumplimiento a rajatabla del contrato en según qué circunstancias, por lo que, en consonancia, se exige a las partes una conducta diligente y previsora en aras de poder eximirse de sus obligaciones. Como consecuencia de ello, ante conductas dolosas o negligentes decaería la posibilidad de aplicar esta doctrina.

Tras examinar la frustration inglesa, es necesario cuestionarse los efectos que tendrá para el contrato, en la medida en que siempre existe la duda entre la renegociación y la extinción del mismo. Antes esta dicotomía la práctica inglesa es clara, se inclina por la extinción del contrato. Esta postura

13 GARCÍA CARACUEL, M., La alteración sobrevenida de las circunstancias contractuales, Madrid, Dykinson, 2014, pág. 89.

14 KATSIVELA, K., "Frustration and impracticability under English, United States (US) and Canadian common law of contracts”, European Transport Law, 1, 2009, págs. 3-27, pág. 10.

15 KATSIVELA, K., "Frustration and impracticability under English, United States (US) and Canadian common law of contracts”, European Transport Law, 1, 2009, págs. 3-27, pág. 11. 
no admite duda alguna por cuanto para la práctica inglesa o se cumple el contrato o se extingue no permitiendo posibilidades que renegocien el contrato ${ }^{16}$. Así pues, con esta premisa, si se estima la doctrina de la frustration, se llevará a cabo la extinción del contrato con efectos desde ese momento.

Así, la finalización del contrato como respuesta a los efectos de la frustration, genera otra cuestión acerca de las prestaciones del contrato. Al fin y al cabo, es preciso tener en cuenta que este tipo de instituciones suelen aplicarse a contratos de tracto sucesivo o de larga duración, por lo que, según las particularidades del mismo, puede que la parte afectada haya tenido que cumplir en gran medida con sus prestaciones, de manera que la extinción no resolvería el problema. Como consecuencia de esta cuestión y guiado por los mismos principios de equidad que justificaron la frustration en su origen, se aprobó una ley de contratos inglesa (Law Reforma Act 1943) que establecía la restitución de prestaciones. Sin embargo, no es una postura que haya tenido una gran acogida y los tribunales siguen manteniendo la tradicional renuencia a aplicar la frustration.

Tras examinar la frustration inglesa, se puede inferir que el Common Law no es muy proclive a tolerar instituciones que afecten al principio pacta sunt servanda, en la medida en que afectan figuras jurídicas relacionadas con la excesiva onerosidad y similares.

Sin embargo, el Derecho norteamericano, pese a su origen común con el Derecho inglés, ha tenido su particular evolución de tal modo que ha generado su propia postura ante este tipo de instituciones jurídicas ${ }^{17}$. Así, en el Derecho norteamericano ha surgido la doctrina de la impracticability que libera al deudor de su obligación si ésta se ha vuelto impracticable.

La doctrina de la impracticability tiene como punto de partida la valoración de las obligaciones desde una perspectiva de su facilidad de ejecutar. Así, esta doctrina considera que una obligación resulta impracticable y, por consiguiente, queda extinta si, alcanza un coste desmesurado e irracional para su cumplimiento ${ }^{18}$. Esta doctrina requiere la valoración de determinadas circunstancias con el objetivo de valorar su presencia o no, de tal modo que los requisitos que deben concurrir son: la presencia de un evento sobrevenido cuya ausencia de previsión forma parte de la premisa básica del contrato, dicho evento sobrevenido debe convertir el cumplimiento de la obligación en impracticable, la parte afectada no debe tener responsabilidad en el evento causante ni éste debe recaer dentro de su ámbito del riesgo.

En cuanto al primer requisito, es obvio que una ruptura del cumplimiento del contrato debe estar justificada por una serie de eventos con una magnitud que respalde la ruptura del pilar básico del derecho de los contratos como es el pacta sunt servanda. Así, además del listado clásico heredado del Common Law inglés como la muerte de las partes o la carestía de bienes necesarios para la ejecución, se añade una categoría de eventos inevitables e imprevisibles. Así, se tiene en consideración que determinados eventos resultarían no habrían sido tenidos en cuenta por las partes a la hora de suscribir el contrato, dado que se trata de eventos inevitables e imprevisibles. Como consecuencia de ello, la ausencia de estos hechos sobrevenidos que no podían ser anticipados por las partes es una

16 GARCÍA CARACUEL, M., La alteración sobrevenida de las circunstancias contractuales, Madrid, Dykinson, 2014, pág. 99.

${ }^{17}$ DIMATTEO, L., "Contractual Excuse under the CISG: Impediment, Hardship, and the Excuse Doctrines", Pace International Law Review, 27, 2015, págs. 258-305, pág. 267.

18 GARCÍA CARACUEL, M., La alteración sobrevenida de las circunstancias contractuales, Madrid, Dykinson, 2014, pág. 110. 
premisa básica del contrato, de manera que la aparición de los eventos puede generar el decaimiento del contrato ${ }^{19}$.

No obstante, no es suficiente con la aparición de dichos eventos, puesto que, si no afectan al desarrollo habitual del contrato, no sería necesario tenerlos en consideración. Por este motivo, hay que tener en cuenta que la aparición de los eventos debe tener su repercusión en el cumplimiento del contrato. Así, los eventos sobrevenidos deben tener incrementar la dificultad de cumplir, un incremento que debe ser irracional, lo que supondría podría equipararse a la alteración del equilibrio existente en otras figuras ${ }^{20}$. Así, el cumplimiento sería técnicamente viable pero no exigible debido a la dificultad que entraña su cumplimiento ${ }^{21}$.

Además de las premisas previas, es necesario que las consecuencias y los eventos no sean provocados por las partes, al fin y al cabo, no hay que olvidar que se pretende alterar el cumplimiento del contrato, por lo que la actuación de las partes no puede ser la que haya provocado los eventos sobrevenidos. De igual modo, hay que tener en cuenta la atribución del riesgo en el contrato, esta figura toma en consideración que la ausencia de estos eventos es una premisa del contrato, por lo que si las partes reparten el riesgo contractual, están, en cierto modo, anticipando la posibilidad de dichos sucesos, lo que rompe la premisa de esta doctrina, además de que el contrato ha atribuido a una parte el deber de soportar ${ }^{22}$.

En caso de poder acreditar la concurrencia de todas las premisas expuestas anteriormente, se aplicaría la doctrina de la impracticability con unas consecuencias tendentes a readaptar el contrato con el fin de mantener su vigencia, aunque permite la extinción en caso de no ser viable la readaptación por no tener sentido23.

Finalizando con esta institución, es necesario detenerse un momento para remarcar que, pese a que el Common Law es un sistema en el que la jurisprudencia ostenta un peso fundamental, esta figura norteamericana ha tenido su repercusión en el derecho positivo, de tal modo que ha sido recogida y aceptada en normas legales. En un primer lugar se reguló en los denominados Restatements, una suerte de complicaciones de argumentos jurisprudenciales, para después ser regulada en el texto por excelencia en materia de contratación, esto es el Uniform Comercial Code24.

\section{La doctrina alemana de la base del negocio}

El derecho alemán de los contratos centra el estudio de estas instituciones relacionadas con la onerosidad sobrevenida en la base del contrato. Así la doctrina alemana viene a denominarse la

\footnotetext{
${ }^{19}$ DIMATTEO, L., "Contractual Excuse under the CISG: Impediment, Hardship, and the Excuse Doctrines", Pace International Law Review, 27, 2015, págs. 258-305, pág. 268.

${ }^{20}$ KATSIVELA, K., "Frustration and impracticability under English, United States (US) and Canadian common law of contracts", European Transport Law, 1, 2009, págs. 3-27, pág. 11.

${ }^{21}$ CHECA MARTÍNEZ, M., "El derecho estadounidense de contratos: del "Common Law" al Código Uniforme de Comercio como código global". En SÁNCHEZ LORENZO, S., Derecho contractual comparado. Una perspectiva europea y transnacional. Tomo I., $3^{a}$ ed., Madrid, Civitas, 2016, págs. 381-428, pág. 408.

${ }^{22}$ KATSIVELA, K., "Frustration and impracticability under English, United States (US) and Canadian common law of contracts", European Transport Law, 1, 2009, págs. 3-27, pág. 17.

${ }^{23}$ GARCÍA CARACUEL, M., La alteración sobrevenida de las circunstancias contractuales, Madrid, Dykinson, 2014, pág. 142.

${ }^{24}$ KATSIVELA, K., "Frustration and impracticability under English, United States (US) and Canadian common law of contracts”, European Transport Law, 1, 2009, págs. 3-27, pág. 12.
} 
teoría de la desaparición de la base del contrato (Geschäftsgrundlage) que constituye la evolución de otra doctrina alemana anterior que comparte cierto núcleo doctrinal y denominada Voraussetzung 25 .

Esta teoría de la base del contrato se relaciona con el consentimiento, pues se entiende que al suscribir el contrato, las partes tienen en cuenta todo un cúmulo de circunstancias que afectan al mismo $^{26}$. Este paradigma que se genera alrededor del contrato y que constituye el fundamento del consentimiento contractual comprende las circunstancias existentes en ese momento y aquellas que las partes deban prever. Así, las circunstancias alrededor de ambas partes construirían un sustrato común que serviría de fundamento al contrato, sin el cual, las partes no se habrían vinculado ${ }^{27}$.

Una vez establecida la base del contrato, es necesario delimitar las premisas que deben concurrir para que pueda aceptarse esta teoría que, igual que el resto, va encaminada a matizar el principio pacta sunt servanda. Así, es preciso que concurran una alteración sustancial de las circunstancias del contrato, la imprevisión por las partes del contrato y la ruptura de la economía del contrato.

En cuanto al primer requisito, es preciso establecer que debe producirse una modificación de las circunstancias del contrato, esta modificación afecta a las circunstancias que constituyen la base del contrato, esto es que forman parte del paradigma contractual que se ha comentado previamente. Dado que dicha base del contrato comprende las circunstancias existentes en el momento de la suscripción y aquellas que deben ser previstas y tenidas en cuenta por las partes, es una consecuencia obvia que la alteración debe escapar de la esfera de control de las partes del contrato ${ }^{28}$.

En relación con el anterior, para la aplicación de esta doctrina debe concurrir la premisa de la imprevisión de las partes. La imprevisión comprende tanto la no anticipación de dichos eventos por las partes como la imposibilidad de cubrir la laguna en la base del contrato que dicha imprevisión genera. En esta doctrina es de capital importancia el paradigma que constituye la base del contrato, por lo que la imprevisión afecta no solo a la no anticipación por las partes, en el sentido de no estar incluido dentro de las circunstancias previstas y, por ende, incluidas, dentro del paradigma que conforma la base del contrato; si no que debe ser imposible integrar la laguna que dichos eventos generan $^{29}$. Así, la imprevisión por las partes exige que con el paradigma que se construye con las circunstancias del contrato y las previsiones que hacen las partes acerca de su evolución no se pueda deducir si las partes desearían continuar vinculadas como consecuencia del cambio de circunstancias.

\footnotetext{
${ }^{25}$ GARCÍA CARACUEL, M., La alteración sobrevenida de las circunstancias contractuales, Madrid, Dykinson, 2014, pág. 219.

${ }^{26} \mathrm{El}$ art. $313.1 \mathrm{BGB}$ permite la adaptación del contrato en caso de gran alteración de circunstancias, siendo esta modificación tan grave que en esa situación las partes no habrían suscrito el contrato. EBERS, M., "La nueva regulación del incumplimiento contractual en el BGB, tras la Ley de modernización del Derecho de obligaciones de 2002”, Anuario de derecho civil, 4, 2003, págs. 1575-1608, pág. 1586.

27 GARCÍA CARACUEL, M., La alteración sobrevenida de las circunstancias contractuales, Madrid, Dykinson, 2014, pág. 228.

28 Esta cuestión permite romper la concurrencia del requisito mediante la introducción en el contrato de cláusulas que amplíen la esfera de riesgo de las partes o repartan los riesgos que puedan surgir con el devenir contractual. MIQUEL SALA, R., "El derecho contractual alemán”. En SÁNCHEZ LORENZO, S., Derecho contractual comparado. Una perspectiva europea y transnacional. Tomo I., $3^{\text {a }}$ edición, Madrid, Civitas, 2016, págs. 285312, pág. 306.

${ }^{29}$ FERNÁNDEZ RUIZ-GÁLVEZ, E., "La alteración sobrevenida de las circunstancias contractuales y la doctrina rebus sic stantibus. Génesis y evolución de un principio jurídico", Persona y derecho: Revista de fundamentación de las Instituciones Jurídicas y de Derechos Humanos, 74, 2016, págs. 291-318, pág. 314.
} 
En cuanto a la última premisa, esto es la alteración de la economía del contrato, hace referencia al desequilibrio y excesiva onerosidad, así como al a frustración del fin del mismo ${ }^{30}$. Por consiguiente, para que se tenga en cuenta esta premisa, debe generarse una alteración que rompe el equilibrio contractual mediante el cual ambas partes de un contrato se obligan porque obtienen una ventaja patrimonial. Si esta ventaja desaparece, se frustraría el fin del contrato y desaparecería la causa por la que han obligado las partes.

Así, la doctrina de la base del contrato construye un paradigma contractual referenciado al momento de suscribir el contrato. Este paradigma se forma por las circunstancias existentes y anticipadas por las partes en el momento de suscribirlo. De tal manera que la alteración rompería la base del contrato, lo que habilitaría a la parte afectada para plantear su extinción ${ }^{31}$.

Una vez delimitadas las premisas de aplicación de dicha teoría, es necesario determinar las consecuencias de su aplicación. Al respecto, se opta por una opción primaria que sería la readaptación del contrato, lo que pone de manifiesto la intención de mantener, en la medida de lo posible, la vigencia de los contratos ${ }^{32}$. Sin embargo, esta solución no se encuentra exenta de críticas, ya que se suele poner en tela de juicio la intervención de un juez para moderar el contrato. En caso de no poderse readaptar el contrato para mantenerlo vigente, debería acudirse a la solución más radical, es decir, la extinción del mismo.

De lo comentado hasta ahora, se puede observar que, aunque haya fundamentos de base diferentes, hay cierta similitud con lo propuesto en los Principios UNIDROIT.

La teoría de la base del contrato resulta sumamente interesante pero resta por esclarecer si se trata de una construcción doctrinal con alguna acogida jurisprudencial o, si por el contrario, ha sido elevada al rango de norma jurídica. Al respecto, dentro de las últimas tendencias existentes en modernizar y actualizar los derechos contractuales nacionales, el derecho alemán no se ha mantenido al margen y ha recogido esta institución en su Código Civil, de modo que se puede encontrar en el art. 313 BGB. Por consiguiente, la teoría de la base del contrato se encuentra incorporada en el derecho positivo, al igual que otras instituciones, no quedando relegada a una doctrina jurisprudencial.

\section{La doctrina de la imprevisión francesa}

La teoría de los contratos francesa contiene una institución dentro de la categoría que está siendo analizada como la excesiva onerosidad que viene a denominarse la teoría de la imprevisión. Sin embargo, se trata de una teoría de construcción doctrinal y con una reacia aceptación por parte de la jurisprudencia ${ }^{3334}$. Esta escasa acogida que tienen este tipo de instituciones no resulta extraña

\footnotetext{
${ }^{30}$ DIMATTEO, L., "Contractual Excuse under the CISG: Impediment, Hardship, and the Excuse Doctrines", Pace International Law Review, 27, 2015, págs. 258-305, pág. 263.

31 FERNÁNDEZ RUIZ-GÁLVEZ, E., "La alteración sobrevenida de las circunstancias contractuales y la doctrina rebus sic stantibus. Génesis y evolución de un principio jurídico”, Persona y derecho: Revista de fundamentación de las Instituciones Jurídicas y de Derechos Humanos, 74, 2016, págs. 291-318, pág. 315.

${ }^{32}$ DIMATTEO, L., "Contractual Excuse under the CISG: Impediment, Hardship, and the Excuse Doctrines", Pace International Law Review, 27, 2015, págs. 258-305, pág. 264.

${ }^{33}$ Resulta destacable la Sentencia de la Cour de cassation de 6 de marzo de 1876, en la que se niega la posibilidad de que un juez modere el contrato. PAZOS CASTRO, R., "La respuesta del derecho de obligaciones y contratos francés ante la pandemia de COVID-19”, Revista de Derecho Civil, 2, 2020, págs. 47-74, pág. 49.

34 GÓMEZ ROJO, M. E., "Algunas aportaciones al análisis de la denominada cláusula rebus sic stantibus. Teoría de la imprevisión. Especial referencia al derecho comparado e internacional (1ªrte)", Revista Europea de Derecho de la Navegación Marítima y Aeronáutica, 18, 2002, págs. 2613-2634, pág. 2623.
} 
por cuanto es la regla general, al menos en sus inicios, en la medida en que implican la matización o choque con el principio pacta sunt servanda.

Por lo que atañe a la teoría de la imprevisión, se produce cuando en un contrato de tracto sucesivo se observa que la ejecución resulta más onerosa de lo esperado en un principio. De tal modo que dicho aumento de la onerosidad trae causa de unas circunstancias sobrevenidas que no pudieron preverse o evitarse ${ }^{35}$. En cuanto a esta definición del cambio de circunstancias, es preciso tener en cuenta que no deben confundirse con otras instituciones como el caso fortuito o la fuerza mayor. No obstante, pese a ser diferente, se articula de forma paralela por cuanto esa imprevisión debe ser justificada por un evento imprevisible e inevitable que suceda de forma sobrevenida.

Así, en la teoría de contratos francesa se estudia si dicha imprevisión altera la economía del contrato, de manera que el consentimiento prestado por las partes deba extenderse a un paradigma que no habían previsto en un principio. Por tanto, se pretende responder si dicho consentimiento se extendería a la nueva situación. Sin embargo, tradicionalmente, la respuesta a esta cuestión ha sido sencilla por cuanto el derecho francés no permite la revisión contractual o extinción por este tipo de situaciones y otras instituciones como el caso fortuito o la fuerza mayor resultarían inaplicables. En este sentido, hay que tener en cuenta que la fuerza mayor se define por la doctrina francesa de una manera sumamente restrictiva, lo cual genera que sea difícil de aplicar y se diferencie del cambio de circunstancias contenido en la teoría de la imprevisión ${ }^{36}$.

Así, el cambio de circunstancias genera onerosidad imprevista, lo que hace difícil cumplir el contrato, pero no alcanza el grado de imposibilidad que requeriría la institución de la fuerza mayor.

Con este punto de partida se orquesta la teoría de la imprevisión que, como se ha indicado, tiene una escasa acogida por parte de la jurisprudencia. Por lo que, se trata de fundamentar dicha teoría acudiendo a diferentes puntos de vista respecto a la interpretación del derecho de los contratos $^{37}$.

En este sentido, se trata la imprevisión desde el punto de la interpretación del contrato y si las partes desean seguir vinculadas. Este punto se ha adelantado y se centra en el consentimiento como fundamento de las obligaciones contractuales. Por lo que las partes se obligan según las circunstancias existentes en ese momento y lo que puedan prever, de tal manera que se podría cuestionar la vigencia del consentimiento ante un evento que altere el paradigma contractual de una manera tal que las partes no hubieran podido prever. Así, la teoría de la imprevisión cuestionaría la extensión del consentimiento a un paradigma que se encuentra más allá de lo previsto por las partes.

En relación con lo anterior y la manifestación del consentimiento, se vincula la teoría de la imprevisión con el análisis de la causa del contrato. Al fin y al cabo, la causa del contrato se encuentra ligada a las circunstancias del mismo, siendo a su vez, sustrato para la generación del consentimiento de las partes. Por este motivo, una alteración sobrevenida de las circunstancias que genere una

\footnotetext{
${ }^{35}$ GARCÍA CARACUEL, M., La alteración sobrevenida de las circunstancias contractuales, Madrid, Dykinson, 2014, pág. 179.

${ }^{36} \mathrm{La}$ aplicación de la fuerza mayor en el derecho francés es sumamente restrictiva por cuanto, incluso en la situación generada por el COVID-19, se discute su aplicación. PAZOS CASTRO, R., "La respuesta del derecho de obligaciones y contratos francés ante la pandemia de COVID-19”, Revista de Derecho Civil, 2, 2020, págs. 47 74, pág. 53.

${ }^{37}$ GARCÍA CARACUEL, M., La alteración sobrevenida de las circunstancias contractuales, Madrid, Dykinson, 2014, pág. 181.
} 
excesiva onerosidad en la ejecución del contrato podría atentar contra la causa del mismo y, por consiguiente, al fundamento del consentimiento manifestado por las partes.

Asimismo, la excesiva onerosidad de la prestación para una de las partes podría traducirse en un enriquecimiento injusto para su contraparte, según las circunstancias. De tal modo que mantener el contrato atentaría contra los principios de buena fe contractual ${ }^{38}$. La intervención de la buena fe en este tipo de instituciones se puede observar en los Principios UNIDROIT.

Pese a la construcción doctrinal en torno a esta institución, la aplicación de la misma resulta excepcional por los tribunales franceses ${ }^{39}$. No obstante, la doctrina trata de alcanzar cierto aperturismo mediante algunas propuestas de reforma del derecho de contratos francés. Así, en los últimos tiempos se han elaborado ciertos proyectos de reforma del derecho de obligaciones con el objetivo de ir reconociendo este tipo de instituciones.

Un primer avance se produjo en 2005 con la presentación del Anteproyecto del Profesor Català que, si bien no reconocía la imprevisión, daba cierta salida a estas situaciones mediante la recomendación a las partes de suscribir cláusulas hardship y a respetar la buena fe negociando los contratos ante situaciones de excesiva onerosidad.

Tras este primer avance, se produjo en 2008 un Proyecto por la Cancillería inspirado en los Principios UNIDROIT en que se reconocía tímidamente la onerosidad adoptando la renegociación del contrato como solución ${ }^{40}$. No obstante, el gran avance se produce en el mismo año con la propuesta elaborada por la Academia de las Ciencias Morales y Políticas que reconocía la teoría de la imprevisión y las cláusulas hardship.

Sin embargo, estos proyectos no constituyen una vinculación más allá del argumento de autoridad, de manera que habría que valorar la Reforma del Código Civil francés que se acometió a nivel legislativo a partir de 2013 y que, parece, recoge las tesis del último proyecto citado. Los proyectos comentados tuvieron que esperar a 2016 para ver consolidados ciertos aspectos ${ }^{41}$. Así, el Gobierno francés obtuvo la autorización para la legislación por ordenanza de tal modo que se reformara el Código Civil francés en materia de obligaciones, elevando, por fin, a rango de derecho positivo la teoría de la imprevisión.

Como consecuencia de ello, en la actualidad, el Código Civil francés acoge la teoría de la imprevisión y permite la readaptación del contrato con la extinción como última opción en caso de no ser viable ${ }^{42}$. Esta regulación se encuentra contenida en el art. 1195 del Código Civil francés, aunque con la peculiaridad de ser dispositiva. De tal manera que las partes pueden hacer una previsión de la imprevisión y, de este modo, distribuir los riesgos contractuales con el fin de anticiparse a los distintos

\footnotetext{
${ }^{38}$ Ese principio de buena fe es lo que lleva a justificar la renegociación del contrato con el fin de devolver el equilibrio contractual, ante una grave alteración de circunstancias. PARRA LUCÁN, M.A., "Riesgo imprevisible y modificación de los contratos”, InDret, 4, 2015, pág. 31.

39 FERNÁNDEZ RUIZ-GÁLVEZ, E., "La alteración sobrevenida de las circunstancias contractuales y la doctrina rebus sic stantibus. Génesis y evolución de un principio jurídico”, Persona y derecho: Revista de fundamentación de las Instituciones Jurídicas y de Derechos Humanos, 74, 2016, págs. 291-318, pág. 312.

${ }^{40}$ GARCÍA CARACUEL, M., La alteración sobrevenida de las circunstancias contractuales, Madrid, Dykinson, 2014, pág. 200 .

41 Ordenanza 2016-131 de 10 de febrero.

42 SAVAUX, E., "El nuevo derecho francés de obligaciones y contratos", Anuario de derecho civil, 3, 2016, págs. 715-741, pág. 732.
} 
eventos que puedan sucederse. Además, otra consecuencia de esta regulación es la intervención dispositiva del juez, en la medida en que dependerá de las partes ${ }^{43}$.

\section{La excesiva onerosidad italiana}

Tras el análisis de las teorías previas, es el momento de examinar la doctrina de la excesiva onerosidad, una teoría de origen italiano cuyo nombre ha sido adoptado por los Principios UNIDROIT. Sin embargo, tal y como se verá, se trata de una doctrina con alguna nota característica sumamente interesante.

La excesiva onerosidad se trata de una institución recogida en el derecho positivo, a diferencia de, por ejemplo, la rebus sic stantibus española, por lo tanto, es una institución que parte con una regulación de partida ${ }^{44}$. Con la premisa de los dispuesto en el texto legal, es posible analizar la institución y utilizar el derecho positivo como punto de partida para examinar la aplicación de la institución.

Así, esta institución jurídica tiene su origen en el Código Civil italiano de 1942 y se define como el mecanismo que permite resolver el contrato cuando, como consecuencia de determinados eventos, se ha tornado excesivamente gravoso o desproporcionado para una de las partes. De esta manera los arts. 1467 a 1469 del Código Civil italiano configuran la excesiva onerosidad estableciendo sus premisas de aplicación y los efectos en el contrato.

Respecto a las premisas para su aplicación, son similares a lo que viene siendo exigible en este tipo de instituciones, por consiguiente, para estimarse la excesiva onerosidad es preciso que concurra un contrato de tracto sucesivo, una alteración del equilibrio contractual como consecuencia de unos eventos imprevisibles e inevitables y que dicha desproporción contractual no sea asumida por las partes ${ }^{45}$. A simple vista, las premisas para la aplicación de la excesiva onerosidad son bastante parecidas a las fijadas por los Principios UNIDROIT. Pese a ello, es necesario examinarlas con el objetivo de clarificar esta institución del derecho italiano.

En cuanto a la primera premisa, es decir, acerca del contrato de tracto sucesivo, es una premisa que tiene su origen en el mismo concepto de la excesiva onerosidad. Así, la excesiva onerosidad pretende combatir el desequilibrio contractual originado por algún tipo de evento imprevisible o inevitable. Como consecuencia de ello, debe transcurrir un período de tiempo entre la suscripción del contrato y su ejecución, de manera que haya un margen temporal para que pueda producirse el evento en cuestión. Por este motivo, dentro de este tipo de instituciones, se ha planteado su limitación a contractos de tracto sucesivo o contratos de ejecución diferida, puesto que, de lo contrario, no tendría sentido valorar un evento imprevisto si apenas ha transcurrido tiempo entre la suscripción del contrato y la ejecución del mismo.

Al fin y al cabo, hay que tener en cuenta que a la hora de valorar los cambios en las circunstancias se realiza un análisis comparativo entre la situación que conocían o debían conocer las

\footnotetext{
${ }^{43}$ QUIÑONES ESCÁMEZ, A., "El derecho contractual francés”. En SÁNCHEZ LORENZO, S., Derecho contractual comparado. Una perspectiva europea y transnacional. Tomo I., $3^{\text {a }}$ ed., Madrid, Civitas, 2016, págs. 243-284, pág. 278.

${ }^{44}$ Se encuentra regulada en la sección $3^{a}$ del capítulo XIV del Título II del Libro IV del Código Civil italiano. CARO GÁNDARA, R., "El modelo contractual italiano”. En SÁNCHEZ LORENZO, S., Derecho contractual comparado. Una perspectiva europea y transnacional. Tomo I., $3^{\text {a }}$ ed., Madrid, Civitas, 2016, págs. 313-380, pág. 368. 45 GARCÍA CARACUEL, M., La alteración sobrevenida de las circunstancias contractuales, Madrid, Dykinson, 2014, pág. 210.
} 
partes en el momento de contratar y la situación en el momento de ejecutar el contrato. De manera que sería sumamente complejo justificar la imprevisibilidad de los eventos cuando la ejecución del contrato es cuasi inmediata tras la suscripción del mismo.

Una vez aclarada esta cuestión que, como se puede inferir, se relaciona íntimamente con el resto de requisitos para estimar la excesiva onerosidad, es inexcusable analizar el desequilibrio contractual. Esta cuestión requiere una labor interpretativa de calado, por cuanto es un concepto jurídico indeterminado que deberá ser concretado caso a caso. No obstante, de forma previa a su aplicación, habrá que extraer ciertos criterios generales que permitan construir una suerte de "test" de la desproporción.

El desequilibrio contractual tiene cierta connotación subjetiva respecto a qué debe ser considerado "excesivo", pero parte de un hecho totalmente objetivo, esto es, la variación del valor de las prestaciones. Así, el estudio de la gran desproporción contractual tiene como punto de inicio una valoración de las prestaciones de las partes. De tal manera que, se podría analizar con objetividad si, por ejemplo, la prestación recibida se ha devaluado o si, por el contrario, la prestación a la que se encuentra obligada una parte ha visto cómo aumenta su coste, aumentando su onerosidad.

A partir del hecho objetivo de la diferencia de valor de las prestaciones, se debe realizar un análisis desde un punto de vista más subjetivo con el fin de establecer si dicho cambio de valor, genera una desproporción entre las prestaciones. Por lo que este criterio subjetivo se irá adaptando caso por caso según las circunstancias de las partes.

Por lo que afecta a los eventos generadores, estos deben ser catalogados como imprevisibles e inevitables. De manera que dichos eventos que provocan el desequilibrio contractual no podían haberse previstos a la hora de contratar o, en caso de ser previstos, deben ser inevitables. Puesto que se toma como referencia el momento de la suscripción del contrato para valorar dichos eventos, es inevitable traer a colación la primera premisa acerca de los contratos de tracto sucesivo, dado que salvo casos muy escasos sería inviable alegar imprevisibilidad de un evento tan dramático como para alterar el contrato.

Finalizando con las premisas de la excesiva onerosidad, hay que comentar la necesidad de que dichos eventos no entren dentro de la esfera del riesgo del contrato ${ }^{46}$. Al fin y al cabo, algunos contratos tienen el riesgo como uno de sus componentes, de tal modo que, las partes asumen que, puedan verse afectados por determinados eventos si éstos pueden ser incluidos dentro de la naturaleza aleatoria del contrato. En este sentido, habría que tener presente contratos tales como los contratos de seguro, contratos de naturaleza especulativa o financieros, entre otros.

Además, la doctrina italiana introduce el criterio de la equidad con el fin de valorar la desproporción y el margen de maniobra de las partes, cuestión interesante por cuanto se relaciona con la tendencia internacional de los Principios UNIDROIT de relacionar la excesiva onerosidad con el principio de buena fe contractual.

Tras revisar los requisitos que deben concurrir para la estimación de la excesiva onerosidad, es imprescindible analizar los efectos que tendrá dicha estimación en el contrato. En este sentido, resulta sumamente notable la solución adoptada en derecho italiano y que se aleja de lo que viene

\footnotetext{
${ }^{46}$ En este sentido, no se puede considerar excesiva a la onerosidad que se sitúa dentro del riesgo contractual asumido por las partes. CARO GÁNDARA, R., "El modelo contractual italiano". En SÁNCHEZ LORENZO, S., Derecho contractual comparado. Una perspectiva europea y transnacional. Tomo I., $3^{a}$ ed. Madrid, Civitas, 2016, págs. 313-380, pág. 368.
} 
siendo lo habitual en este tipo de instituciones ${ }^{47}$. Las instituciones que se están tratando en el presente trabajo suponen una ruptura del principio fundamental del derecho de los contratos pacta sunt servanda. Por este motivo, la solución habitual es la de tratar de mantener vigente el contrato mediante la renegociación o readaptación del mismo, en un intento de no romper frontalmente con el citado principio.

Sin embargo, en el derecho italiano se opta por la resolución contractual como remedio preferente, de tal manera que, si concurren los requisitos expuestos, la parte afectada podrá instar la resolución del contrato ${ }^{48}$. Así, se fija la resolución contractual como la solución principal, cuando la tónica habitual viene siendo su admisión de forma subsidiaria. Ante la aplicación de la excesiva onerosidad y la resolución contractual, la contraparte solo puede oponerse proponiendo una modificación contractual que devuelva el equilibrio perdido al contrato ${ }^{49}$.

\section{La cláusula rebus sic stantibus}

Dentro del conjunto de instituciones jurídicas que matizan el principio pacta sunt servanda, es preciso detenerse en la doctrina española y la cláusula rebus sic stantibus.

Esta institución se diferencia de otras en que no se encuentra regulada, ha sido creada por la práctica, de tal manera que ha tenido una paulatina construcción jurisprudencia a través de varios fallos del Tribunal Supremo ${ }^{50}$. Por consiguiente, habrá que estar a lo dispuesto por el Alto Tribunal en los numerosos fallos en los que trate esta institución, con el objetivo de esclarecer los requisitos que deben concurrir para su aceptación.

Por ello, el punto de partida es la renombrada Sentencia del Tribunal Supremo de 17 de mayo de 1957 (ROJ STS 127/1957), puesto que se trata de un fallo en el que se establecen los requisitos para la aplicación de la cláusula rebus sic stantibus. Así, esta resolución constituye un punto de partida, por cuanto hace una labor de construcción de la institución definiendo las premisas para su aplicación. Del citado fallo, se pueden inferir que las circunstancias que deben concurrir para la aplicación de la cláusula rebus sic stantibus son la alteración grave de las circunstancias, una gran desproporción entre las prestaciones de las partes y que todo ello sea consecuencia de unos eventos imprevisibles.

En cuanto a la alteración grave de las circunstancias, debe establecerse el momento de referencia, puesto que debe haber una alteración con respecto a otro momento en concreto. En este sentido, se toma como referencia el momento de celebración del contrato. De tal modo que, si un observador externo analizara las circunstancias alrededor del contrato en el momento en que las partes lo suscribieron y se comparan con las circunstancias en el momento de ejecutarlo, se verá una enorme diferencia entre ellas.

\footnotetext{
47 Aunque en los ordenamientos estudiados en el presente trabajo existe la vía de la adaptación contractual, es una vía no exenta de críticas debido a la intervención de un tercero en el contrato suscrito por las partes, lo que supone una injerencia en la voluntad de las partes. PARRA LUCÁN, M.A., "Riesgo imprevisible y modificación de los contratos", InDret, 4, 2015, pág. 36.

48 GARCÍA CARACUEL, M., La alteración sobrevenida de las circunstancias contractuales, Madrid, Dykinson, 2014, pág. 215.

49 PARRA LUCÁN, M.A., "Riesgo imprevisible y modificación de los contratos”, InDret, 4, 2015, pág. 37.

50 ÁLVAREZ ROYO-VILLANOVA, S., "Pandemia, fuerza mayor y 'cláusula rebus sic stantibus' a la luz de la jurisprudencia”, Diario La Ley, 9619, 2020, pág. 2.
} 
Sin embargo, los requisitos de la cláusula rebus sic stantibus son cumulativos, de tal manera que la alteración grave de las circunstancias no es más que el punto de partida para delimitar si cabría la aplicación de dicha institución. Por consiguiente, esa alteración grave de las circunstancias debe abrir paso a una grave desproporción entre las prestaciones contractuales ${ }^{51}$. Así, producido el desequilibrio entre las partes se pueden valorar diferentes puntos. Por un lado, es posible atender al fin del contrato y valorar que, como consecuencia de ese desequilibrio, se ha frustrado el fin del contrato, en la medida en que una de las partes no logrará alcanzar la satisfacción de sus legítimas expectativas contractuales. Por otro lado, también se puede considerar que dicho desequilibrio afectaría al consentimiento contractual, en la medida en que si las partes hubieran podido prever este desarrollo de los acontecimientos no habrían decidido obligarse al contrato.

No obstante, el principio pacta sunt servanda no puede alterarse así como así, motivo por el que, además de los requisitos expuestos, debe concurrir la imprevisibilidad de los acontecimientos. Esta cuestión es sumamente interesante en la medida en que puede enlazar con otras instituciones conocidas como el deber de diligencia en el cumplimiento de los contratos.

Así, como premisa de partida, es necesario delimitar la esfera de control de las partes, de tal manera que puedan determinar hasta dónde debería llegar la debida diligencia y el deber de previsión de una parte contratante. Esta labor no deja de ser harto compleja en la medida en que la imprevisibilidad no deja de ser un concepto impreciso que necesita una labor de adecuación a la práctica. En este sentido, resulta necesaria la doctrina jurisprudencia que aplica la cláusula rebus sic stantibus con el fin de analizar este requisito.

Respecto a la práctica jurisprudencial y la aplicación de la imprevisibilidad, se puede observar cómo el Tribunal Supremo introduce un nuevo concepto, el de la razonabilidad, con el fin de tratar de aclarar la aplicación del requisito de la imprevisibilidad ${ }^{52}$. Así, es posible que las circunstancias en sentido estricto no fueran del todo imprevisibles, pero sí unas consecuencias devastadoras.

Además, resulta interesante traer a colación determinados análisis de la imprevisibilidad que la relacionan con el riesgo contractual asumido por las partes. De tal manera que determinados acontecimientos que, en principio podrían ser susceptibles de recaer bajo la rebus sic stantibus, quedarían excluidos en la medida en que las partes habrían asumido ciertos riesgos respecto a las circunstancias contractuales.

La razonabilidad y análisis de la imprevisibilidad caso a caso lleva a concluir que habrá determinados contratos que quedarían, por su naturaleza, excluidos de la rebus sic stantibus. Con ánimo esclarecedor, se pueden traer a colación aquellos contratos de naturaleza puramente especulativa, donde el riesgo se encuentra en su naturaleza, dado que en el riesgo y la posible ventaja que de él derive, reside el interés de las partes en contratar. En esta línea se han producido diversos fallos relacionados con contractos del ámbito financiero en los que el riesgo de la pérdida total se asume

\footnotetext{
${ }^{51}$ Esa gran desproporción es la vía de entrada para principios de justicia material y buena fe que algunos autores esgrimen como fundamentos de la extinción contractual por la cláusula rebus sic stantibus. ESTRUCH ESTRUCH, J., "La aplicación de la cláusula rebus sic stantibus”, Revista Crítica de Derecho Inmobiliario, 780, 2020, págs. 2037-2095, pág. 2072.

${ }^{52}$ La razonabilidad permite valorar la imprevisibilidad al hilo de las circunstancias, en este sentido, se realizó una aplicación razonable de la imprevisibilidad de la crisis económica de 2008. MARTÍNEZ VELENCOSO, L. M., "Confirmación de la doctrina jurisprudencial de la Sala 1a del Tribunal Supremo en torno a la cláusula 'rebus sic stantibus'. (Comentario de la STS de 15 de octubre de 2014)”, Revista Aranzadi Doctrinal, 2, 2015, págs.111-114, pág. 113.
} 
por las partes como algo inherente al contrato, motivo por el que las posibilidades de eventos imprevisibles se reducen sensiblemente ${ }^{53}$.

Una vez comentados los requisitos que deben concurrir para la correcta aplicación de la cláusula rebus sic stantibus, es necesario centrarse en las consecuencias de su aplicación. Esta cuestión es sumamente espinosa y fruto de una reciente evolución, ya que la institución objeto de estudio evoluciona según diferentes situaciones de crisis.

Respecto a la aplicación de la rebus sic stantibus, surge una dicotomía respecto a la readaptación del contrato o la extinción del mismo ${ }^{54}$. En este sentido, es preciso destacar que esta figura surge como una matización del principio pacta sunt servanda y que sería menos radical inclinarse por la opción de la readaptación contractual ${ }^{55}$. Así, mediante esta solución, se matizaría un principio nuclear del derecho de contratos, pero con el objetivo de mantener vivo el contrato. Esta postura ha sido la recogida tradicionalmente por el Tribunal Supremo, quien ha mantenido una postura cautelosa al respecto. Además, ciertos sectores de la doctrina consideran que la rebus sic stantibus no puede conllevar la resolución contractual, dado que ya existe la figura de la imposibilidad sobrevenida, institución que sí permitiría la resolución contractual.

Sin embargo, el Tribunal Supremo ha ido abriendo la puerta a incluir la resolución contractual dentro del ámbito de la cláusula rebus sic stantibus. Así, la Sentencia del Tribunal Supremo de 6 de marzo de 2020 incluye la resolución contractual dentro de las posibilidades que permitirían solventar situaciones de grave desequilibrio en sede de la rebus sic stantibus.

No obstante, no se trata de una postura unánime y solo se han producido tímidos reconocimientos por parte del Tribunal Supremo sin llegar a constituir esta postura una jurisprudencia consolidada. Pese a ello, es innegable que la resolución contractual se abre paso, en la medida en que se contempla en la Propuesta de Modificación del Código Civil.

Esta propuesta de reforma que no se encuentra en vigor, resulta sumamente interesante en la medida en que propone una redacción del art. 1213 CC en qué eleva al rango de norma la figura de la rebus sic stantibus y que contempla la resolución contractual como opción, aunque de manera subordinada a la imposibilidad de readaptar el contrato ${ }^{56}$.

\section{Conclusión}

Una vez vistas las diferentes figuras relativas al hardship o excesiva onerosidad existentes en los ordenamientos jurídicos, es preciso determinar la tendencia convergente en relación a la fase de actualización del derecho de contratos a la que se asiste en los últimos tiempos.

\footnotetext{
${ }^{53}$ HERRERO URTUETA, E., "La imprevisibilidad en la rebus sic stantibus a propósito de la Sentencia de la Audiencia Provincial de Barcelona 178/2020 de 22 de mayo”, Diario La Ley, 9781, 2021, pág. 3.

54 Algunos autores consideran que la extinción del contrato es doctrinalmente excluyente con la cláusula rebus sic stantibus y su naturaleza de conservación del contrato. BENÍTEZ RODRÍGUEZ, D., "Rebus sic stantibus. Fundamento y efecto", Revista Aranzadi Doctrinal, 9, 2020, pág. 16.

55 Se ha generado cierta vinculación entre el principio de buena fe contractual y la readaptación del contrato como consecuencia de la rebus sic stantibus. LÓPEZ MOLINA, M., "Lidiando con lo imprevisible. Consecuencias jurídicas, contractuales, de acontecimientos inesperados y posibles soluciones legales", Diario La Ley, 9639,2020, pág. 2.

${ }^{56}$ SALVADOR CODERCH, P., "Alteración de circunstancias en el art. 1213 de la Propuesta de Modernización del Código Civil en materia de Obligaciones y Contratos”, InDret, 4, 2009, pág. 6.
} 
Así, en un mundo cada vez más globalizado como es el actual, es preciso realizar un estudio comparativo de las diferentes instituciones, en la medida en que los contratos internacionales tienen cada vez mayor peso en el ámbito contractual. Por este motivo, se ha partido de la institución de la excesiva onerosidad contemplada en los Principios UNIDROIT, de manera que se pueda observar el funcionamiento y premisas de partida de la citada figura jurídica en el ámbito internacional.

En los Principios UNIDROIT se construye una institución que permite la renegociación contractual y, como última opción, la extinción del contrato como consecuencia de una ruptura del equilibrio contractual surgido de un cambio brusco de las circunstancias contractuales. Dada la importancia de la contratación internacional, resulta reseñable que un instrumento del soft law que tiene tanto prestigio, acoja una institución que ha sido largamente discutida en el seno de los diferentes ordenamientos por su vocación rupturista con el principio pacta sunt servanda. A mayor abundamiento, aunque no es el objeto del presente trabajo, es interesante que un instrumento cómo la Convención de Viena sobre contratos de compraventa internacional de mercaderías ha generado un debate en el seno de su art. 79 CISG acerca de si el hardship o excesiva onerosidad tiene cabida en ella.

Con todo ello se pretende ilustrar la enorme dificultad que existe para una aprobación más o menos generalizada de instituciones de este tipo en el ámbito nacional. Por lo que, en el ámbito de la contratación internacional, la cuestión es más compleja, en la medida en que para la aprobación de cualquier instrumento se requiere la anuencia de Estados diferentes con sistemas jurídicos diferentes. $\mathrm{Al}$ fin y al cabo, los Principios UNIDROIT no son vinculantes al ser parte del soft law, aunque su autoridad y referencia están fuera de discusión.

De todo lo anteriormente dicho, se puede observar un panorama en el que esta institución, que ha tenido una evolución complicada en cada ordenamiento, tiene cierta presencia en el ámbito de la contratación internacional a través de los Principios UNIDROIT que son el reflejo, en cierta medida, de los diferentes ordenamientos jurídicos.

Así, en los diferentes derechos nacionales estudiados se observa que, pese a la trayectoria individual que han tenido, fruto de pertenecer a diferentes familias jurídicas, han regulado instituciones diferentes pero sumamente coincidentes entre sí, en cuanto a las premisas básicas se refiere. En líneas generales todas las instituciones estudiadas pretenden romper el absolutismo del principio pacta sunt servanda con el objetivo de paliar las consecuencias perniciosas que puedan generar diferentes eventos que rompen el equilibrio contractual. Por todo ello, la premisa de desequilibrio contractual como consecuencia de eventos imprevisibles e inevitables es común a todas las instituciones, salvando las distancias en relación a la naturaleza de los eventos y su posible relación con otras figuras como el caso fortuito o fuerza mayor.

Además, en las consecuencias, también suele haber cierto consenso en el sentido de otorgar prioridad a la conservación del contrato, motivo por el que la aplicación de estas instituciones suele establecer como medida principal la renegociación del contrato, relegando la extinción como consecuencia drástica y residual. Sin embargo, en este sentido comienzan a verse las diferencias originadas por las diferentes familias jurídicas, puesto que la frustration inglesa es muy restrictiva en su aplicación, pero no contempla la readaptación, teniendo como consecuencia la extinción del contrato.

Por lo que, de todo lo anteriormente visto, se puede valorar que son instituciones sumamente parecidas, aunque la mayor diferencia radica en el fundamento teórico y doctrinal sobre el que incide la institución, fruto de la particular idiosincrasia de su derecho contractual. Así, unas figuras ponen el foco en la voluntad de las partes y si ésta puede considerarse prestada con un cambio brusco del paradigma contractual, mientras que otras en el desequilibrio de las prestaciones o la base del negocio 
jurídico. Sin embargo, pese a las diferencias doctrinales, tienen un sustrato común que se puede orquestar alrededor de dos puntos.

El primero de ellos versa acerca del consentimiento prestado por las partes, en la medida en que se valora que la voluntad de obligarse al contrato se lleva a cabo teniendo presente un paradigma circunstancial y su posible evolución, dentro de una variabilidad razonable, de tal modo que se cuestiona el consentimiento contractual si algún evento de gran magnitud rompe dicho paradigma considerado en el momento de la suscripción del contrato.

En cuanto al segundo de los puntos, gira alrededor del equilibrio de las prestaciones y cómo ese equilibrio, que implica la ventaja que cada una de las partes pretende obtener del contrato, además de ser fundamento del consentimiento, lo que lo relaciona con el punto anterior, es una manifestación del principio de buena fe contractual, lo que permitiría la entrada en escena de estas instituciones con el fin de evitar "disfuncionalidades" como el enriquecimiento injusto entre otras.

Recapitulando, se ha visto que en el ámbito contractual internacional se ha construido una figura de la excesiva onerosidad en el seno de unos Principios UNIDROIT que no son vinculantes, al constituir el soft law, además de la enorme dificultad de lograr el consenso suficiente para redactar un tratado en esta materia por la barrera de conjugar diferentes ordenamientos jurídicos. Sin embargo, analizando la evolución particular de diferentes derechos nacionales, no cabe duda de que se está en una fase de modernización del derecho de contratos con una clara tendencia a incorporar estas instituciones. Asimismo, las diferentes figuras jurídicas que se han ido construyendo en los derechos nacionales tienen ciertas notas comunes entre sí, por lo que se puede entrever una tendencia común cuyo exponente lo constituyen los Principios UNIDROIT. Al fin y al cabo, si estos principios se nutren de los diferentes derechos nacionales y, simultáneamente, son tomados como referencia a la hora de actualizar los derechos nacionales, no resulta extraño que se esté generando un sustrato común en sede de excesiva onerosidad. Como consecuencia de ello, se está produciendo una armonización del derecho de contratos mediante la vía de la legislación nacional convergente ${ }^{57}$.

\section{Bibliografía}

ÁLVAREZ ROYO-VILLANOVA, S., "Pandemia, fuerza mayor y 'cláusula rebus sic stantibus' a la luz de la jurisprudencia”, Diario La Ley, 9619, 2020.

BASEDOW, J., "Towards a Universal Doctrine of Breach of Contract: The Impact of the CISG", International Review of Law and Economic, 25, 2005, pp. 487-500.

BENÍTEZ RODRÍGUEZ, D., "Rebus sic stantibus. Fundamento y efecto", Revista Aranzadi Doctrinal, 9, 2020.

CARO GÁNDARA, R., “El modelo contractual italiano”. En SÁNCHEZ LORENZO, S., Derecho contractual comparado. Una perspectiva europea y transnacional. Tomo I., $3^{a}$ ed., Civitas, Madrid, 2016, pp. 313-380.

CHECA MARTÍNEZ, M., "El derecho estadounidense de contratos: del 'Common Law' al Código Uniforme de Comercio como código global”, en S. Sánchez Lorenzo, Derecho contractual

\footnotetext{
57 Algunos autores han analizado la regulación convergente que se está produciendo en los diferentes ordenamientos jurídicos nacionales, lo que pone de relieve la importancia de los diversos instrumentos internacionales que sirven como referencia. BASEDOW, J., "Towards a Universal Doctrine of Breach of Contract: The Impact of the CISG”, International Review of Law and Economics, 25, 2005, págs. 487-500.
} 
comparado. Una perspectiva europea y transnacional. Tomo I., $3^{\text {a }}$ ed., Civitas, Madrid, 2016, pp. 381 428.

DÍEZ SOTO, C. M. y GONZÁLEZ PACANOWSKA, I. V., "Los principios de UNIDROIT sobre los contratos comerciales internacionales y los efectos derivados del Covid-19 sobre las relaciones contractuales: una perspectiva desde el Derecho español", Cuadernos de derecho transnacional, 1, 2021, pp. 180-237.

DIMATTEO, L., "Contractual Excuse under the CISG: Impediment, Hardship, and the Excuse Doctrines”, Pace International Law Review, 27, 2015, pp. 258-305.

EBERS, M., "La nueva regulación del incumplimiento contractual en el BGB, tras la Ley de modernización del Derecho de obligaciones de 2002", Anuario de derecho civil, 4, 2003, pp. 1575-1608.

ESTRUCH ESTRUCH, J., "La aplicación de la cláusula rebus sic stantibus”, Revista Crítica de Derecho Inmobiliario, 780, 2020, pp. 2037-2095.

FERNÁNDEZ RUIZ-GÁLVEZ, E., "La alteración sobrevenida de las circunstancias contractuales y la doctrina rebus sic stantibus. Génesis y evolución de un principio jurídico", Persona y derecho: Revista de fundamentación de las Instituciones Jurídicas y de Derechos Humanos, 74, 2016, pp. 291-318.

GARCÍA CARACUEL, M., La alteración sobrevenida de las circunstancias contractuales, Dykinson, Madrid, 2014.

GÓMEZ ROJO, M. E., “Algunas aportaciones al análisis de la denominada cláusula rebus sic stantibus. Teoría de la imprevisión. Especial referencia al derecho comparado e internacional (1'a parte)", Revista Europea de Derecho de la Navegación Marítima y Aeronáutica, 18, 2002, pp. 26132634.

HERRERO URTUETA, E., "La imprevisibilidad en la rebus sic stantibus a propósito de la Sentencia de la Audiencia Provincial de Barcelona 178/2020 de 22 de mayo”, Diario La Ley, 9781, 2021.

ILLESCAS ORTIZ, R. y PERALES VISCASILLAS, P. (2003). Derecho mercantil internacional. El Derecho uniforme, Centro de Estudios Ramón Areces, Madrid, 2003.

KATSIVELA, K., "Frustation and impracticability under English, United States (US) and canadian common law of contracts", European Transport Law, 1, 2009, pp. 3-27.

LÓPEZ MOLINA, M., "Lidiando con lo imprevisible. Consecuencias jurídicas, contractuales, de acontecimientos inesperados y posibles soluciones legales", Diario La Ley, 9639,2020.

MARTÍNEZ VELENCOSO, L. M., “Confirmación de la doctrina jurisprudencial de la Sala 1a del Tribunal Supremo en torno a la cláusula 'rebus sic stantibus'. (Comentario de la STS de 15 de octubre de 2014)", Revista Aranzadi Doctrinal, 2, 2015, pp. 111-114.

MIQUEL SALA, R., “El derecho contractual alemán”. En S. Sánchez Lorenzo, Derecho contractual comparado. Una perspectiva europea y transnacional. Tomo I., $3^{\text {a }}$ ed., Civitas, Madrid, 2016, pp. 285312.

PARRA LUCÁN, M.A., "Riesgo imprevisible y modificación de los contratos”, InDret, 4, 2015.

PAZOS CASTRO, R., "La respuesta del derecho de obligaciones y contratos francés ante la pandemia de COVID-19", Revista de Derecho Civil, 2, 2020, pp. 47-74. 
QUIÑONES ESCÁMEZ, A., "El derecho contractual francés”. En S. Sánchez Lorenzo, Derecho contractual comparado. Una perspectiva europea y transnacional. Tomo I., $3^{a}$ ed., Civitas, Madrid, 2016, pp. 243-284.

SALVADOR CODERCH, P., "Alteración de circunstancias en el art. 1213 de la Propuesta de Modernización del Código Civil en materia de Obligaciones y Contratos”, InDret, 4, 2009.

SAVAUX, E., "El nuevo derecho francés de obligaciones y contratos", Anuario de derecho civil, 3, 2016, pp. $715-741$.

TIMOTEO, M., "Desequilibrios contractuales y adecuación del contrato en los Principios UNIDROIT", Revista de Derecho Mercantil, 228, 1998, pp. 1269-1284.

VIGURI PEREA, A., Los contratos comerciales internacionales: análisis de la compraventa desde la perspectiva del derecho comparado (Derecho español, Derecho norteamericano, Principios Unidroity Convención de Viena). Centro de Estudios del Colegio de Registradores de la Propiedad y Mercantiles de España, Madrid, 2007. 